\title{
Mental health and psychosocial support in humanitarian emergencies
}

M. van Ommeren, ${ }^{1}$ F. Hanna, I. Weissbecker ${ }^{2}$ and P. Ventevogel ${ }^{3}$

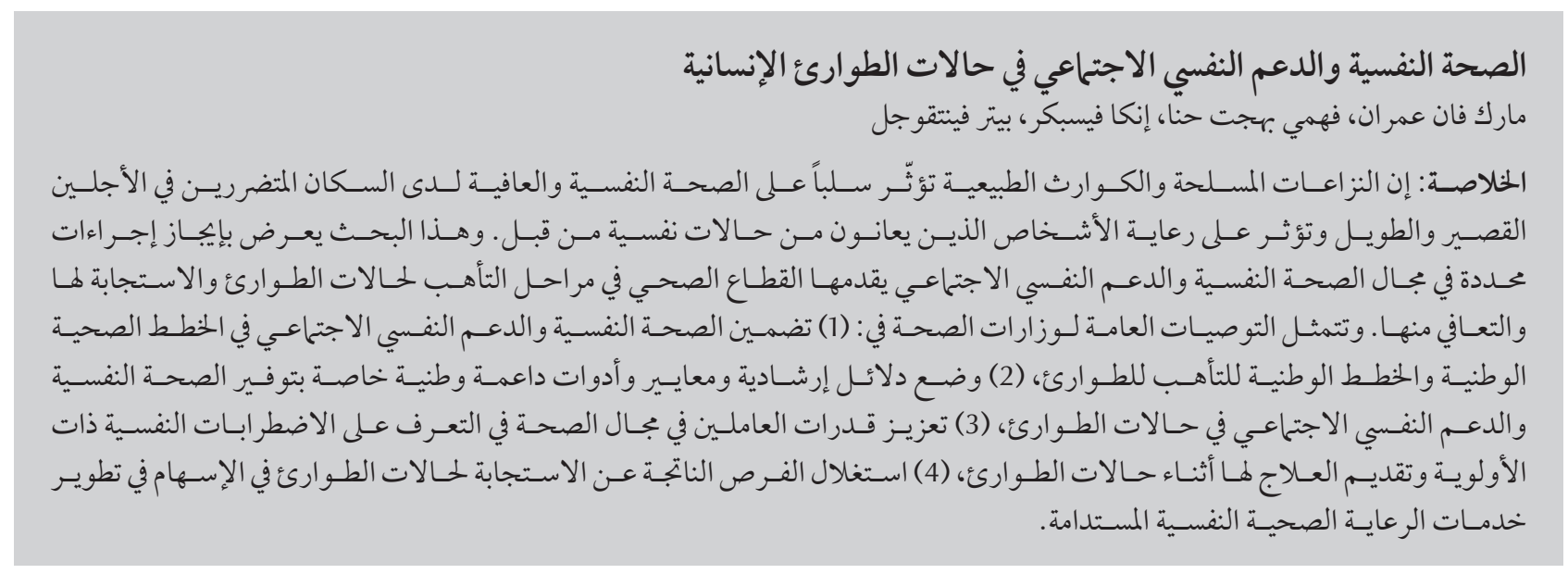

ABSTRACT Armed conflicts and natural disasters impact negatively on the mental health and well-being of affected populations in the short- and long-term and affect the care of people with pre-existing mental health conditions. This paper outlines specific actions for mental health and psychosocial support by the health sector in the preparedness, response and recovery phases of emergencies. Broad recommendations for ministries of health are to: (1) embed mental health and psychosocial support in national health and emergency preparedness plans; (2) put in place national guidelines, standards and supporting tools for the provision of mental health and psychosocial support during emergencies; (3) strengthen the capacity of health professionals to identify and manage priority mental disorders during emergencies; and (4) utilize opportunities generated by the emergency response to contribute to development of sustainable mental health-care services.

Santé mentale et soutien psychosocial en situation d'urgence humanitaire

RÉSUMÉ Les conflits armés et les catastrophes naturelles ont des répercussions négatives sur la santé mentale et le bien-être des populations touchées à court et long termes et affectent la prise en charge des personnes atteintes de troubles de santé mentale préexistants. Le présent article détaille les actions spécifiques en matière de santé mentale et de soutien psychosocial menées par le secteur de la santé dans les phases de préparation aux situations d'urgence, d'organisation des secours et de relèvement. Les recommandations générales destinées aux ministères de la Santé sont les suivantes : 1) intégrer la santé mentale et le soutien psychosocial dans les plans nationaux de santé et de préparation aux situations d'urgence ; 2) mettre en place des directives et des normes nationales, et des outils d'appui pour la santé mentale et le soutien psychosocial en situations d'urgence; 3) renforcer les capacités des professionnels de santé à identifier et prendre en charge les troubles de santé mentale prioritaires en situations d'urgence ; et 4) exploiter les opportunités générées par la riposte aux situations d'urgence pour contribuer à la mise en place de services de soins de santé mentale pérennes.

'Department of Mental Health and Substance Abuse, World Health Organization Headquarters, Geneva, Switzerland (Correspondence to M. van Ommeren: vanommerenm@who.int). ${ }^{2}$ International Medical Corps, Washington DC, United States of America. ${ }^{3}$ Public Health Section, Office of the United Nations High Commissioner for Refugees, Geneva, Switzerland. 
The case for mental health \& psychosocial support in emergency settings

Armed conflicts and natural disasters cause not only physical injuries but also major psychological and social suffering that undermines the long-term mental health and well-being of the affected populations. This in turn may ultimately be a threat to peace, human rights and economic development. People with pre-existing or emergency-induced mental health conditions can be especially vulnerable in humanitarian emergencies, while facilities for mental health care are often directly affected by emergencies, causing disruption of regular services and interruption of ongoing treatments. Yet there are effective individual, group and population level mental health and psychosocial interventions that can be applied in emergencies. Among the many priorities in emergencies, therefore, is the protectio+ $n$ and improvement of people's mental health and psychosocial well-being. This requires coordinated, cross-sectoral action (1-3).

WHO estimates that after an acute onset major emergency on average about 1 in 6 people (10-15\%) will suffer a mild to moderate mental disorder. In addition, about 1 in 30 people (3-4\%) will have a mental disorder that is so severe that it undermines their ability to function and survive in a chaotic emergency environment (4). Mental health and psychosocial problems are frequently raised as an issue by the media, governments and humanitarian agencies during high-profile emergencies, but they need similar attention during all kinds of humanitarian emergencies including protracted emergencies that fall "out of the spotlight" of the media.

This paper summarizes the key actions for mental health and psychosocial support (MHPSS) by the health sector in the preparedness, response and recovery phases of emergencies.

\section{Preparedness phase: planning}

In the preparedness phase for MHPSS in emergency settings, which is part of national emergency planning, it is recommended to:

- embed MHPSS in national health policies and strategies and emergency preparedness plans;

- map existing formal and non-formal resources and practices in MHPSS (5);

- orient staff in the health, protection and other sectors as well as workers in the community in "psychological first aid" (6);

- train and supervise health-care staff in the management of priority mental health conditions that are relevant to emergencies, using the World Health Organization (WHO) and United Nations High Commissioner for Refugees (UNHCR), Mental Health Gap Action Programme (mhGAP) Humanitarian intervention guide (mhGAP-HIG) (7);

- prepare emergency stocks of essential psychotropic medications. At a minimum there should be availability of amitriptyline (or fluoxetine), phenobarbital (or carbamazepine), biperiden, haloperidol and diazepam (8);

- develop emergency preparedness plans for people with severe or chronic mental illness residing in institutions and in the community, as per Action Sheet 6.3 of the Inter-Agency Standing Committee (IASC) Guidelines for mental health and psychosocial support in emergency settings, 2007) (1)

\section{Response phase: action}

\section{Assessment of MHPSS needs}

Assessment of MHPSS needs during the response phase should involve mapping of existing resources and capacities, including what is being done by organizations and how affected people are coping. Tools exist to conduct MHPSS assessments of needs and resources (5). Assessments and situational analyses have been conducted in various countries of the Eastern Mediterranean Region by United Nations' agencies (9) and nongovernmental organizations such as the International Medical Corps (e.g. in Libya and Jordan, available at http://www.mhpss.net).

The provision of essential MHPSS services should not be delayed by assessments, but should go hand-in-hand with them.

During a humanitarian crisis epidemiological surveys to estimate the prevalence of mental disorders are not needed to justify investing in MHPSS or to start planning services. In specific cases, and if well conducted, prevalence surveys can be justified, for example to inform advocacy efforts and to add to the current scientific evidence.

\section{Coordination of MHPSS interventions}

In order to coordinate interventions in the response phase MHPSS activities need to be discussed and integrated within the work plans of the relevant sectors, especially those in health, protection and education. MHPSS does not constitute a separate cluster or sector and therefore accountability for MHPSS activities remains within the relevant clusters or sectors. In order to avoid fragmentation of MHPSS over various clusters or sectors in emergencies with numerous MHPSS managers it is recommended to establish a crosssectoral MHPSS working group with strong functional links to (sub) clusters or sectors for health, protection, child protection, sexual and gender-based violence and education, and co-chaired by a health agency and a protection agency. The group can provide a forum for information exchange by mapping the situation, for example using the $4 \mathrm{Ws}$ tool (Who is doing What Where and 
until When) (10), by cross-sectoral multi-agency assessments and by organizing joint workshops and trainings.

\section{Provision of MHPSS interventions}

\section{Mental health interventions in non- specialized health settings}

Non-specialist health staff, with a brief training and good clinical supervision, are able to provide basic evidencebased interventions for people with mental, neurological and substance use disorders in emergencies. Every health facility in an emergency setting (including mobile clinics, general hospitals, field hospitals, primary health care facilities) should have at least one staff member who is trained and supervised to identify and manage mental health problems in adults and children. It is recommended to base this on the guidance of the WHO/ UNHCR's mhGAP-HIG (7). The Interagency Emergency Health Kit specifies certain essential medicines for mental health care in emergencies (8).

\section{Evidence-based psychological inter- ventions}

Some evidence-based psychological interventions (e.g. cognitive-behaviour therapy, interpersonal therapy and stress management) could potentially be implemented by lay workers, provided they are well trained and supervised (11). However, many popular generic counselling programmes lack a robust evidence base. Some psychological interventions can even be harmful when implemented by undertrained, unsupervised helpers. One-off sessions of so-called "psychological debriefing" have been found to be ineffective and potentially harmful and their use should be discouraged (12).

\section{Supervision and referral pathways}

Mental health interventions at the lower levels of the health-care system must be supported by mental health services at higher levels of the health system, through ongoing clinical supervision and referral options.

\section{Psychological first aid}

Community workers, including volunteers, as well as staff involved in providing various services and activities (e.g. health facilities, child friendly spaces, schools, protection services), can offer psychological first aid to people in acute distress (5). Orientation seminars in psychological first aid can be brief, as little as a half day or one day (13).

\section{Protection of people with severe men- tal disorders}

It is essential to address the safety, basic needs and rights of people with severe mental health problems in institutions and in the community in times of humanitarian emergency. Mental hospitals and residential homes for people with severe mental problems need to be visited regularly, especially in conflict settings, because severe neglect and abuse of people in institutions is common in emergencies. Safety, basic physical needs (water, food, shelter, sanitation and medical care), human rights surveillance and basic psychiatric and psychosocial care must be provided throughout the crisis. People with severe mental disorders in the community and their care-givers also need access to appropriate support, information and mental health services.

\section{Collaboration}

\section{Dissemination of information}

Lack of information is a key concern and a major source of anxiety in populations affected by humanitarian emergencies. It is therefore important to disseminate information to the community on the current emergency situation, relief efforts and available services and supports. This may be done through various media, including bulletin boards and pamphlets at health-care facilities.

Links between different levels of services People with mental health and psychosocial problems may have major challenges in accessing mental health care as well as other basic support and services. Within each emergency, systems should be developed to link vulnerable individuals to the assistance they need. One way to do this is by adding case managers or MHPSS outreach workers to health services. Links should also be established between different levels of mental health support and services (e.g. links from the community level to facility-based clinical mental health services).

\section{Community support}

It is useful to engage community workers and volunteers in order to strengthen self-help and social support among community members, including marginalized groups. This can include:

- early childhood development activities (especially important in food crises) $(14,15)$;

- support for emergency relief (e.g. building shelters) that is initiated by the community;

- support for social support activities that are initiated by the community; and

- facilitation of community support to marginalized people including people with mental disorders.

\section{Early recovery}

It is necessary to initiate plans and create the momentum to develop a sustainable community mental health system as part of an early recovery phase.

\section{Recovery phase: opportunities}

A number of countries in the world, especially in the Eastern Mediterranean Region, have seized opportunities during and after emergencies to build better mental health-care services $(21,22)$. Emergencies often mobilize considerable attention towards, and resources for, the psychological 


\section{Box 1 Case study on mental health and psychosocial support in humanitarian emergencies: experiences from Libya}

Decades of neglect and the 2011 conflict left Libya's mental health system with only 12 psychiatrists. Libya's services had been highly centralized in psychiatric hospitals in the main urban centres of Tripoli and Benghazi, and the country did not have a postgraduate training programme in mental health. During 2011, hundreds of Libyans with war-related symptoms or pre-existing mental disorders aggravated by the emergency flocked to the few existing mental health facilities seeking treatment from a system that was unable to cope.

A new mental health programme led by the Libyan Ministry of Health and the Libyan National Centre for Disease Control, and supported by WHO, aimed to transform Libya's institution-based and centralized approach to mental health care into to a decentralized and community-based approach. The goal was to make mental health services available to the most remote and underserved areas of the country through capacity-building of professionals of many disciplines. This included a diploma course for general practitioners in primary mental health care and a diploma course for psychologists in psychotherapeutic interventions. Candidates for the two intensive training programmes were selected from underserved areas.

The programme led to the creation of multidisciplinary teams that provided services in geographical locations where no mental health services existed. Specialists were assigned to Ministry of Health mobile teams to support and supervise these new services. Hundreds of service users have been using outpatient multidisciplinary services every month. In 2013 the programme trained psychiatrists, nurses, social workers, volunteers and programme managers. It also ran advocacy campaigns to raise awareness about mental health among the public and professionals, in order to combat stigma and facilitate the introduction of the new community-based services to different geographical areas. Long-term training programmes have been designed and will be implemented to establish the first locally graduated Libyan psychiatrists (18).

In 2014, the political and security situation in Libya markedly deteriorated, which disrupted many training activities and compromised the presence of international organizations in the country. However, despite the political upheaval, some of the recently trained local professionals in Libya started to provide services in new locations in 2014. The first community mental health centre in Kufra opened in the south of the country and new mental health clinics were established in the cities of Ajdabya and Zawia. Service provision in these new mental health facilities is provided by multidisciplinary teams of Libyan professionals, who have continued, against the odds, to provide services for the people of their country.

\section{Box 2 Case study of reorganization of mental health services in humanitarian settings from Jordan}

The influx of displaced, war-affected Iraqis into Jordan has drawn substantial mental health support from aid agencies and short-term humanitarian funds from donors. Within this context, the Ministry of Health of Jordan and WHO initiated a mental health programme in 2008 to provide community-based mental health care to Iraqis and Jordanians, through the adoption of a comprehensive, multidisciplinary, biopsychosocial approach (16).

Collaboration with a range of stakeholders, led by the Ministry of Public Health, has been key towards the setting up of integrated mental health services. Jordan was one of the first countries to pilot the Mental Health Gap Action Programme (mhGAP). So far, approximately 90 general health workers at 21 primary health-care centres in three governorates (four cities) have been trained on the mhGAP base course, and continue to receive monthly supervision and follow-up. Four community mental health centres (outpatient centres) in Amman, Irbid and Ma'an-staffed by multidisciplinary teams including psychiatrists, psychologists, social workers and nurses-provide comprehensive care in the community. A model acute inpatient unit was set up at the National Centre for Mental Health which has led to three further mental health inpatient units at King Abdullah Hospital (Irbid), Jordan University Hospital (Amman) and Ma'an Governmental Hospital (Ma'an). The first organization representing mental health service users and their families (Our Step Association) is dedicated to supporting people with mental health problems through advocacy, awareness, fighting stigma and promoting mental health and human rights in the community. The Association works closely with WHO and the Jordanian Ministry of Health outpatient centres to provide vocational, rehabilitation, educational and recreational activities to its members. In 2013, the Association started using the WHO Quality Rights Toolkit to provide support to improving the rights of service users at facilities (17).

The plans are to scale up the integration of mental health in primary health care through the implementation of mhGAP in three governorates (Ma'an, Tafilah, Zarqa) and to establish inpatient and outpatient mental health units in Zarqa.

For further information see the following: the chapter on Jordan in the WHO's 2013 publication Building back better: sustainable mental health care after emergencies (16); YouTube videos on Mental health reform in Jordan $(18,19)$; and the WHO MiNDbank database of resources for Jordan (20). 
welfare of affected people, while decision-makers become more willing to consider options beyond the status quo. The media frequently highlights the psychological suffering of survivors and this may increase the willingness and financial ability of national and international agencies to support mental health and psychosocial assistance to affected people. Therefore, humanitarian emergencies may create unique opportunities for better and more sustainable mental health services. Momentum needs to be generated at an early stage so that investments continue after an acute crisis. See Boxes 1 and 2 for cases studies from Libya and Jordan.

\section{Key recommendations for ministries of health}

- Embed MHPSS in national health and emergency preparedness plans.
- Put in place national guidelines, standards and supporting tools for the provision of MHPSS during emergencies.

- Strengthen the capacity of health professionals to identify and manage priority mental disorders during emergencies.

- Utilize opportunities generated by the emergency response to contribute to the development of sustainable mental health-care services.

\section{References}

1. IASC Guidelines for mental health and psychosocial support in emergency settings. Geneva: Inter-Agency Standing Committee; 2007.

2. Humanitarian charter and minimum standards in disaster response. Geneva: The Sphere Project; 2011.

3. Operational guidance: mental health and psychosocial support programming for refugee operations. Geneva: United Nations High Commissioner for Refugees; 2013.

4. Van Ommeren M, Saxena S, Saraceno B. Aid after disasters. BMJ. 2005 May 21;330(7501):1160-1. PMID:15905230

5. Assessing mental health and psychosocial needs and resources: toolkit for humanitarian settings. Geneva: World Health Organization and United Nations High Commissioner for Refugees; 2012.

6. Psychological first aid: guide for field workers. Diemen, The Netherlands: War Trauma Foundation and World Vision International; 2013.

7. Mental Health Gap Action Programme humanitarian intervention guide (mhGAP-HIG): clinical management of mental, neurological and substance use conditions in humanitarian emergencies. Version 1.0. Geneva: World Health Organization and United Nations High Commissioner for Refugees; 2015 [in press].

8. Van Ommeren M, Barbui C, de Jong K, Dua T, Jones L, PerezSales $P$, et al. If you could only choose five psychotropic medis cines: updating the interagency emergency health kit. PLoS Med. 2011 May; 8(5): e1001030. PMID:21559326

9. MHPSS situation analysis: IDP and refugee crisis Kurdistan, Northern Iraq (KRG) February 19-March 10 (internal document). Geneva: World Health Organization and United Nations High Commissioner for Refugees; 2015.

10. Who is where, when, doing what (4Ws) in mental health and psychosocial support: manual with activity codes (field test version). Geneva: Inter-Agency Standing Committee, Reference Group on Mental Health and Psychosocial Support in Emergency Settings; 2012.

11. Patel V, Chowdhary N, Rahman A, Verdeli H. Improving access to psychological treatments: lessons from developing countries. Behav Res Ther. 2011 Sep;49(9):523-8. PMID:21788012
12. Rose S, Bisson J, Churchill R, Wessely S. Psychological debriefing for preventing post traumatic stress disorder (PTSD). Cochrane Database Syst Rev. 2002;(2):CD000560. PMID: 12076399.

13. Psychological first aid: facilitator's manual for orienting field workers. Geneva: World Health Organization, War Trauma Foundation and World Vision International; 2013

14. Mental health and psychosocial well-being among children in severe food shortage situations. Geneva: World Health Organization; 2006.

15. Integrating early childhood development (ECD) activities into nutritional programmes in emergencies: why, what and how. Geneva: World Health Organization and United Nation's Children's Fund; 2012.

16. Building back better: sustainable mental health care after emergencies. Geneva: World Health Organization; 2013.

17. QualityRights tool kit to assess and improve quality and human rights in mental health and social care facilities. Geneva: World Health Organization; 2012.

18. Mental health reform in Jordan. English version, Part 1. YouTube [Internet] (http://www.youtube.com/ watch? $=$ =m7Xq96eGZCw, accessed 5 April 2015).

19. Mental health reform in Jordan. English version, Part 2. YouTube [Internet] (http://www.youtube.com/ watch? $v=$ DaZrDTfZ6KA, accessed 5 April 2015).

20. Country resources: Jordan. WHO MiNDbank: more inclusiveness needed in disability and development [Internet] (http:// www.mindbank.info/collection/country/jordan, accessed 5 April 2015).

21. Epping-Jordan JE, van Ommeren M, Ashour HN, Maramis A, Marini A, Mohanraj A, et al. Beyond the crisis: building back better mental health care in 10 emergency-affected areas using a longer-term perspective. Int J Ment Health Systems. 2015;9(1):15.

22. Review of the implementation of the IASC guidelines on mental health and psychosocial support in emergency settings. Geneva: Inter-Agency Standing Committee Reference Group; 2015. 